Research Letter

\title{
Morphological study of the internal organs in rats with alloxan diabetes and transplanted liver tumor after intravenous injection of gold nanorods
}

\author{
Natalya I. Dikht ${ }^{1}$, Alla B. Bucharskaya ${ }^{1}$, Georgy S. Terentyuk ${ }^{1}$, Galina N. Maslyakova ${ }^{1}$, Olga V. Matveeva ${ }^{1}$, \\ Nikita A. Navolokin ${ }^{1}$, Nikolai G. Khlebtsov ${ }^{2}$, Boris N. Khlebtsov ${ }^{2}$ \\ ${ }^{1}$ Saratov State Medical University n.a.V.I.Razumovsky, Saratov, Russia \\ ${ }^{2}$ Institute of Biochemistry and Physiology of Plants and Microorganisms of Russian Academy of Sciences, Saratov, Russia
}

Received 27 August 2014, Accepted 08 September 2014

(C) 2014, Dikht N.I., Bucharskaya A.B., Terentyuk G.S., Maslyakova G.N., Matveeva O.V., Navolokin N.A., Khlebtsov N.G., Khlebtsov B.N.

(C) 2014, Russian Open Medical Journal

Abstract: The effects of gold nanorods to internal organs and liver tumors were studied in rats with combined pathology - alloxan diabetes and transplanted liver tumors at single intravenous administration. The evaluation of morphological and functional changes and gold biodistribution in the internal organs and transplanted liver tumor were conducted. It was found that single intravenous injection of gold nanorods did not cause significant morphological changes in the inner organs and tumor. There was a significant accumulation of gold in the liver and spleen in animals in all experimental groups.

Keywords: gold nanorods, alloxan diabetes, transplanted liver tumor, morphological study

Cite as Dikht NI, Bucharskaya AB, Terentyuk GS, Maslyakova GN, Matveeva OV, Navolokin NA, Khlebtsov NG, Khlebtsov BN. Morphological study of the internal organs in rats with alloxan diabetes and transplanted liver tumor after intravenous injection of gold nanorods. Russian Open Medical Journal 2014; 3: 0301 .

Correspondence to Prof. Galina N. Maslyakova. Address: Saratov State Medical University, 121, Bolshaya Kazachya str., Saratov, 410012, Russia. E-mail: gmaslyakova@yandex.ru

\section{Introduction}

The diabetes mellitus takes the fourth place among the causes of premature mortality. Recent estimates of World Health Organization indicate that there were 171 million people in the world with diabetes in 2000 and it is projected to increase to 366 million in 2030 [1]. Numerous epidemiological studies have demonstrated an association between increased risk of cancer development and progression and type 2 of diabetes mellitus as well as obesity $[2,3]$.

The lack of effectiveness of therapy methods of diabetes and malignant tumors causes the search of new treatment technologies. The active use of nanotechnologies in diagnostics and treatment of different diseases and pathological processes is currently one of the promising areas of its biomedical applications [4]. The considerable amount of scientific reports was devoted to the interactions between different types of nanoparticles and cells [5]. Despite a progress in the application of nanotechnologies in practical biology and medicine, the mechanisms of the possible side effects of nanoparticles are still poorly understood [6, 7].

The gold nanoparticles show great potential as photothermal therapy agents and as imaging agents in connection with its important properties: biocompatibility, high surface reactivity, resistance to oxidation and plasmon resonance [8].

\section{Material and Methods}

In experiments the gold nanorods length of $41 \pm 8 \mathrm{~nm}$ and a diameter of $10.2 \pm 2.0 \mathrm{~nm}$, synthesized in a laboratory of nanobiotechnologies (Institute of Biochemistry and Physiology of Plants and Microorganisms of Russian Academy of Sciences, Saratov, Russia), were used. At synthesis of PEG-coated gold nanorods the following reagents were used: silver nitrate $\left(\mathrm{AgNO}_{3}\right)$ (>99.9\%; Aldrich, 20.913-9), cetyltrimethylammonium bromide (CTAB) (96\%; Fluka, USA, № 52370), chloroauric acid $\left(\mathrm{HAuCl}_{4}\right)$ (>99\%; Aldrich, USA), iso-ascorbic acid (AsA) (>99\%; Fluka, USA), sodium borohydride (Sigma-Aldrich, USA), hydrochloric acid (OFS, Vekton, Russia), potash (OFS, Reahim, Russia), polyethylene glycol-thiol (PEG-SH) (5000, Nektar, USA), water Milli Q. The first synthesis step was mixed successively $0.1 \mathrm{ml}$ of $1 \mathrm{M} \mathrm{CTAB}, 25$ I of $10 \mathrm{mM} \mathrm{HAuCl}_{4}$ and $100 \mathrm{ul}$ of $10 \mathrm{mM}$ sodium borohydride solution. After the addition of $\mathrm{HAuCl}_{4}$ mixture changes the color from colorless to yellow after the addition of sodium borohydride color immediately changed into pale brown, indicating the formation of gold nanoparticles of 1-3 nm in diameter. Germinal solution was left without stirring, without closing the lid for 30-120 minutes. Next, $2 \mathrm{ml}$ of a $4 \mathrm{mM}$ solution of silver nitrate, $5 \mathrm{ml}$ of a $10 \mathrm{mM}$ solution of $\mathrm{HAuCl}_{4}, 1 \mathrm{ml}$ of $100 \mathrm{mM}$ solution of ascorbic acid, $1 \mathrm{ml}$ of $1 \mathrm{M}$ hydrochloric acid, $1 \mathrm{ml}$ of gold nuclei were added successively to $100 \mathrm{ml}$ of $0.1 \mathrm{M}$ solution of CTAB. The resulting suspension was heated at $28^{\circ} \mathrm{C}$ for 24 hours. As a result, a suspension of gold nanorods. CTAB was coated with gold concentration of about $80 \mathrm{ug} / \mathrm{ml}$ and an optical density of 3.5-4.0 
at $1 \mathrm{~cm}$ cuvette at wavelength of the plasmon resonance. The resulting suspension was centrifuged gold nanorods during 1 hour at $14,000 \mathrm{~g}$. The pellet containing the nanoparticles was dissolved in the same volume of water. $1 \mathrm{ml}$ of a $0.2 \mathrm{M}$ solution of potassium carbonate and $1 \mathrm{ml}$ of $1 \mathrm{mM}$ solution of PEG-SH was added to 100 $\mathrm{ml}$ of the nanoparticle suspension. The suspension is kept for 12 hours at $28^{\circ} \mathrm{C}$ and centrifuged for 1 hour at $14,000 \mathrm{~g}$. The precipitate was dissolved in $100 \mathrm{ml}$ of water. The procedure of centrifugation, redissolution was repeated 5 times, after which the solution was concentrated to a gold concentration $400 \mathrm{ug} / \mathrm{ml}$. Geometrical parameters nanorods were determined by transmission electron microscopy (TEM) images obtained by electron microscope Libra-20 (Carl Zeiss, Germany).

The experimental study was performed at Center of Collective Use of Saratov State Medical University n.a. V.I. Razumovsky (Saratov, Russia) on 48 healthy mature albino male rats weighing 180-220 g. In developing the model of experimental study we relied on the guidance "International Guiding principles for Biomedical Research Involving Animals» [9].

Animals were randomly divided into 4 groups of 12 animals per group: the first experimental group with alloxan diabetes, the second experimental group with transplanted liver cancer, the third experimental group with alloxan diabetes and transplanted liver cancer and the control group. Prior some medical procedure or treatment, the rats were anaesthetized with Zoletil 50 (Virbac, France).

The experimental diabetes induced by intraperitoneal injection of a single dose of alloxan monohydrate $-100 \mathrm{ug} / \mathrm{kg}$ body weight. After administration of alloxan the determination of blood glucose level was carried by Accu-Chek PerformaRoche (Switzerland). On the 15th day 6 rats were removed from the experiment by decapitation.

The experimental model of rat liver cancer was reproduced by transplantation of tumor cells suspension of liver cancer (cholangiocarcinoma line PC-1), obtained from the bank of tumor strains of Russian Cancer Research Center n.a. N.N. Blokhin. On the 30th day after transplantation 6 rats were removed from the experiment by decapitation.

In the third group on the $15^{\text {th }}$ day after alloxan injection the liver tumor was transplanted. The modeling diabetes and transplantation tumor carried out similar to methods described above. On the $30^{\text {th }}$ day after transplantation 6 rats were removed from the experiment by decapitation.

All remaining in the experiment rats were injected intravenously gold nanoparticles in amount $2 \mathrm{ml}$ with gold concentration $400 \mathrm{ug} / \mathrm{ml}$. 24 hours after injection all animals were deduced from experiment and tissue samples of internal organs and tumors for morphological studies were collected. The standard histological techniques with hematoxylin and eosin and Periodic acid-Schiff (PAS) staining were used.

Morphometric analysis of histological preparations was performed using digital image analysis system "Medical Microvizor" $\mu$ Vizo-101 (LOMO, Russia). For the statistical analysis of the results of these studies «SPSS 17.0» program was used.

\section{Results}

After administration of alloxan the significant elevation of serum glucose was observed: through 10 days - up to $12.34 \pm 2.86 \mathrm{mmol} / \mathrm{l}$, through 15 days - up to $18.39 \pm 3.49 \mathrm{mmol} / \mathrm{I}$ which far exceeded the control values $(p<0.05)$. The animals showed clinical manifestations of diabetes - polydipsia, polyuria.

On the $15^{\text {th }}$ day after alloxan injection the morphological changes of varying severity were observed in histological sections of rats with simulated diabetes compared with the control group. In the liver the structure architectonic was persisted, in hepatocytes the carbohydrate dystrophy with varying degrees of severity was developed, the plethora was detected in the central venous and sinusoids. The significant decrease in the accumulation of glycogen in the liver was noted compared with the control at PAS staining (absence of positive PAS-reaction). This is due to a decrease of tissue glycogen reserves in the liver after damage to the insulin-producing $\beta$-cells of pancreatic islets and development of alloxan diabetes.

In the spleen the white pulp was presented by lymph follicles without light centers, the pigment granules were located in the red pulp, there was a slight predominance of red pulp over white. Characteristic structural and functional changes in the kidney at diabetes associated with glycosuria. In the kidney the carbohydrate dystrophy of tubular epithelium developed, there was necrosis of individual cells. A decrease in the lumen of tubular epithelial cells, increase in size of epithelial cells and cystic transformation of the tubules were noted. The glycogen infiltration of the epithelium of the tubules was revealed, mainly in the apical part of the cytoplasm and in the basement membrane. In the tubular lumen PAS-positive content was marked that reflects the increased synthesis of glycogen in the tubular epithelium at resorption of glucose-rich plasma ultrafiltrate (Figures $1 \mathrm{a}$ and $1 \mathrm{~b}$ ). In glomeruli the plethora with different degree of expression and in some cases the thickening of Bowman-Shymlansky capsule were noted; in small arterioles the plasmatic impregnation was revealed, the atrophy of the urothelium was marked in pelvis.

In the pancreas hyperemia and focal perivascular sclerosis were marked, pancreatic acini were closely adjacent to each other. In animals with alloxan diabetes, the number and size of pancreatic islets were reduced, while the islets had many signs of degeneration (see Figure 1d).
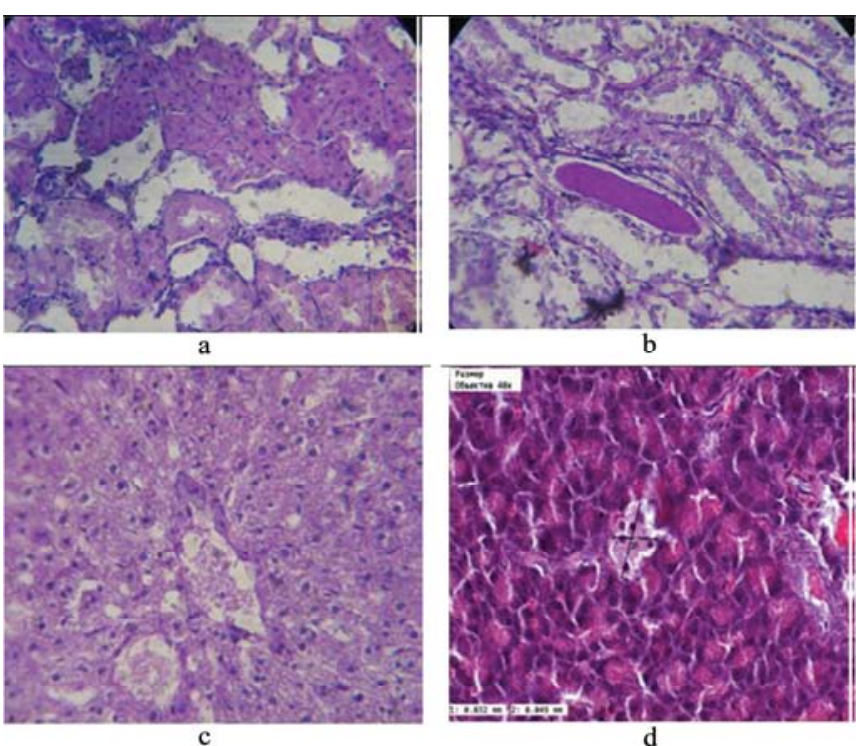

Figure 1. Kidney of rats wit alloxan diabetes: Hematoxylin (a) and eosin (b), x200. Liver (c) and pancreas (d) of rat with alloxan diabetes: PASreaction, $\mathbf{x} 200$. 


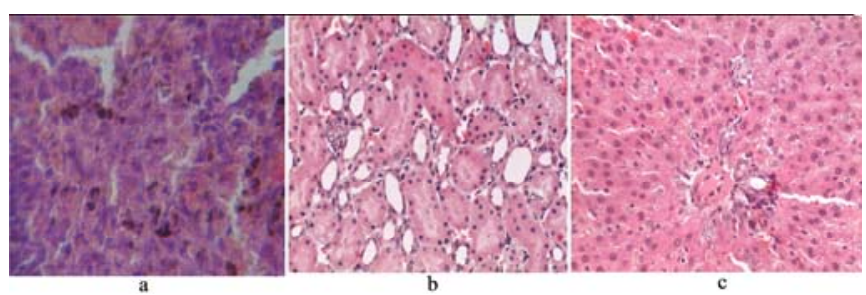

Figure 2. Spleen (a), kidney (b) and liver (c) after intravenous injection of gold nanorods in the control group of animals. Hematoxylin and eosin. $\mathbf{x} 200$.

The atrophy of endocrine islets associated with selective destruction of $\beta$-cells. At development of alloxan diabetes the changes of the vascular wall such as a plasmatic impregnation associated with hyperglycemia took place as the first stage of changes in blood vessels, leading eventually to the development of diabetic microangiopathy.

At morphological studies of the second group of animals with cholangiocarcinoma there were no significant structural changes in the liver, kidney and spleen in comparison with the control group. Pancreas retained normal structure of acini and islets of Langerhans. In parenchymal organs (liver, kidneys) the signs of impaired blood supply were expressed, degeneration of cells and edema were observed in the stroma. These morphological changes can be explained by the presence of intoxication effects of growing tumors on the body of animals.

Morphologically tumors in the second group of rats had a lobed structure; segments were separated by thin layers of connective tissue. Tumor cells had oval-rounded shape with eccentrically located nuclei. A significant portion of cytoplasm was occupied by large vacuoles containing mucus. There were clusters of mucous masses in the intercellular spaces.

At study in the third group of animals with alloxan diabetes and transplanted liver tumor we revealed that the tumor transplantation changes progress of experimental diabetes. 10 days after tumor transplantation blood glucose level returned to normal (to $5.7 \pm 0.7 \mathrm{mmol} / \mathrm{l}$ ). The reducing of tumor growth was noted in third group of animals. The tumor weight $17.6 \pm 2.3 \mathrm{~g}$ accounted in group with diabetes, in comparison group $26.9 \pm 3.1 \mathrm{~g} 30$ days after transplantation).

The increase in the area of necrosis $(20.0 \%$ compared with $12.5 \%$ in the control group) and the decrease of the mitotic activity ( 12 to 1000 cells in comparison with 23 to 1000 cells in the second experimental group) were observed in tumors of this group of animals.

The characteristic for diabetes changes were observed at morphologic study of the liver, pancreas and kidneys in animals with diabetes and transplanted tumor. The liver had expressed granular degeneration of hepatocytes, including necrosis of individual cells.

The marked PAS-positive reaction in the form of a homogeneous granularity in the cytoplasm of hepatocytes was noted in the liver of animals with diabetes and transplanted tumor, which indicates an increase of glycogen accumulation.

One day after intravenous gold nanorods significant morphological changes in the internal organs of the rats in the control group were not observed. In the spleen the stroma had normal structure, reticulum cells and reticular fibers were presented, the boundary between the red and white pulp was clearly discernible. In the white pulp of the amount of lymphatic follicles and their size and dimensions did not differ from the control group. In the red pulp the moderate hyperemia and marked accumulation of pigment granules were detected (Figure 2a).

In the kidney medulla the glomeruli was of normal size. Tubules had a rounded shape; the lumen was free or in some cases slightly tapered by reason of increasing the size of the epithelial cells. Tubular epithelial cells were slightly enlarged, the cytoplasm in a state of granular dystrophy (Figure 2b). Basal membrane of tubules did not changed. Cortical stroma was presented by loose fibrous connective tissue; the moderate hyperemia of the cortical layer was noted.

The liver structure was preserved; the stroma was represented by connective tissue stroma layers, which were located in welldefined interlobular arteries, veins, and bile ducts. Interlobular bile ducts were lined by a single layer of cuboidal epithelium, signs of inflammation or stagnation of bile were not revealed. Liver parenchyma had normal structure and was presented by well distinguishable hepatic lobules. The moderately pronounced hyperemia was noted (Figure $2 \mathrm{c}$ ).

The character of revealed morphological changes in the internal organs of control group of animals after intravenous administration of gold nanorods coincides with previously obtained our data about morphological changes after intravenous injection of gold nanoparticles [10].

One day after the intravenous administration of gold nanorods the significant changes were not found in the internal organs and transplanted liver tumors in all experimental groups of rats.

\section{Conclusion}

The most pronounced morphological changes were noted in the kidney of rats with diabetes such as carbohydrate dystrophy of tubular epithelium, plethora of glomeruli and development of plasmatic impregnation in the walls of small arterioles.

Transplantation of liver tumors alters the course of experimental diabetes which manifested in normalization of blood glucose levels in observed group of animals, the marked slowing of tumor growth, increase of the area of necroses and decrease of the mitotic activity of the tumor cells.

Intravenous injection of gold nanorods did not cause significant morphological changes in the internal organs and transplanted tumors in rats in all experimental groups, which is probably due to the short period of observation after administration of the nanoparticles.

Conflict of interest: none declared.

\section{References}

1. Definition and diagnosis of diabetes mellitus and intermediate hyperglycemia. Report of a WHO/IDF consultation. WHO, 2006; 50 p.

2. Müssig K, Staiger H, Kantartzis K, Fritsche A, Kanz L, Häring HU. Diabetes, insulin, insulin analogues, and cancer. Dtsch Med Wochenschr 2010; 135(18): 924-929. (doi: 10.1055/s-0030-1253681)

3. Grote VA, Becker S, Kaaks R. Diabetes mellitus type 2 - an independent risk factor for cancer? Exp Clin Endocrinol Diabetes 2010; 118(1): 4-8. (doi: 10.1055/s-0029-1243193)

4. Nanomedical device and systems design nanomedical device and systems design: challenges, possibilities, visions. F. Boehm eds. CRC Press, 2013; $787 \mathrm{p}$. 
5. Lecture notes in nanoscale science and technology \#7: Nanoparticles and nanodevices in biological applications. The Infn Lectures - Vol I. S. Bellucci eds. Springer, 2008; 210 p.

6. Lewinski N, Colvin V, Drezek R. Cytotoxicity of nanoparticles. Small 2008; 4(1): 26-49. (doi: 10.1002/smll.200700595) (PMID: 18165959)

7. Gil PR, Oberdörster G, Elder A, Puntes V, Parak WJ. Correlating physico-chemical with toxicological properties of nanoparticles: The present and the future. ACS Nano 2010; 4(10): 5527-5531. (doi: 10.1021/nn1025687)

8. Khlebtsov NG, Dykman LA. Biodistribution and toxicity of engineered gold nanoparticles: a review of in vitro and in vivo studies. Chem Soc Rev 2011; 40: 1647-1671. (doi: 10.1039/c0cs00018c) (PMID: 21082078)

9. International Guiding Principles for Biomedical Research Involving Animals, CIOMS\&ICLAS, 2012. http://www.cioms.ch/index.php/12newsflash/227-cioms-and-iclas-release-the-new-international-guidingprinciples-for-biomedical-research-involving-animals.

10. Terentyuk GS, Maslyakova GN, Suleymanova LV, Khlebtsov BN, Kogan BYa, Akchurin GG, et al. Circulation and distribution of gold nanoparticles and induced alterations of tissue morphology at intravenous particle delivery. J Biophoton 2009; 2(5): 292-302. (doi: 10.1002/jbio.200910005) (PMID: 19434616)

Authors:

Natalya I. Dikht - PhD, assistant of Endocrinology Department, Saratov State Medical University n.a.V.I.Razumovsky, Saratov, Russia;

Alla B. Bucharskaya - PhD, Head of Centre of Collective Use, Scientific Research Institute of Fundamental and Clinical Uronephrology, Saratov State Medical University n.a.V.I.Razumovsky, Saratov, Russia;

Georgy S. Terentyuk - D.Sc., Professor, Senior Research Scientist of Centre of Collective Use, Scientific Research Institute of Fundamental and Clinical Uronephrology, Saratov State Medical University n.a.V.I.Razumovsky, Saratov, Russia;

Galina N. Maslyakova - MD, D.Sc., Professor, Head of Department of Pathology Anatomy, Saratov State Medical University n.a.V.I.Razumovsky, Saratov, Russia;

Olga V. Matveeva - PhD, Research assistant of Centre of Collective Use, Scientific Research Institute of Fundamental and Clinical Uronephrology, Saratov State Medical University n.a.V.I.Razumovsky, Saratov, Russia;

Nikita A. Navolokin - Research assistant of Centre of Collective Use, Scientific Research Institute of Fundamental and Clinical Uronephrology, Saratov State Medical University n.a.V.I.Razumovsky, Saratov, Russia;

Nikolai G. Khlebtsov - D.Sc., Professor, Head of Laboratory of Nanobiotechnology, Institute of Biochemistry and Physiology of Plants and Microorganisms of Russian Academy of Sciences, Saratov, Russia;

Boris N. Khlebtsov - D.Sc., Senior Researcher, Laboratory of Nanobiotechnology, Institute of Biochemistry and Physiology of Plants and Microorganisms of Russian Academy of Sciences, Saratov, Russia. 